\title{
Enhanced Controlled Transdermal Delivery of Torasemide Using Ethylene-vinyl Acetate
}

\author{
Cheong-Weon Cho ${ }^{1}$, Jun-ShikChoi ${ }^{2}$ and Sang-ChulShin ${ }^{{ }^{*}}$ \\ ${ }^{1}$ College of Pharmacy, Chungnam National University, Daejeon 305-764, ${ }^{2}$ College of Pharmacy, Chosun University, \\ Gwangju 501-759, ${ }^{3}$ College of Pharmacy, Chonnam National University, Gwangju 500-757, Korea.
}

\begin{abstract}
Purpose: To develop an ethylene-vinyl acetate (EVA) matrix system containing a permeation enhancer for enhanced transdermal delivery of torasemide.

Methods: The solubility of torasemide was studied at various volume fraction of polyethylene glycol (PEG) 400. The effect of drug concentration was tested at 1.0, 2.0 and $3.0 \%$, respectively while the effect of temperature on drug release from drug-EVA matrix was evaluated at $27,32,37$ and $42{ }^{\circ} \mathrm{C}$. To increase pore size and flexibility of the EVA matrix, plasticizers with citrate and phthalate groups were added to the matrix containing torasemide. To improve the penetration of torasemide from the EVA matrix across the skin, enhancers (propylene glycol derivatives, fatty acids, glycerides, pyrrolidones and non-ionic surfactants) were incorporated into the torasemide-EVA matrix. The effects of the enhancers on the skin penetration were evaluated using Franz diffusion cell fitted with the intact excised rat skin.

Results: Solubility and permeation of torasemide was highest at $40 \% \mathrm{v} / \mathrm{v}$ PEG 400 . The release rate of drug from drug-EVA matrix increased with increased loading dose and temperature. Release rate was proportional to the square root of loading dose. The activation energy $\left(E_{a}\right)$, which was derived from the slope of $\log P$ versus $1000 / T$, was $14.95 \mathrm{kcal} / \mathrm{mol}$ for $2.0 \%$ loading dose. Among the plasticizers used, diethyl phthalate showed the highest release rate of torasemide. Among the enhancers used, polyoxyethylene 2-oleyl ether showed the greatest enhancing effect.

Conclusion: For the enhanced controlled transdermal delivery of torasemide, the application of the EVA matrix containing plasticizer and penetration enhancer could be useful in the development of a transdermal drug delivery system.
\end{abstract}

Keywords: Torasemide, Ethylene-vinyl acetate, Controlled transdermal delivery, Matrix, Plasticizer, Permeation enhancer 


\section{INTRODUCTION}

Torasemide has been used to treat edema and primary hypertension and to prevent kidney stones [1]. However, it often causes many side effects on gastrointestinal system such as gastric irritation, nausea, and vomiting with repeated oral administration. Therefore, it is necessary to consider alternative routes for administration of torasemide to avoid these adverse effects. Transdermal drug delivery is able to avoid the harmful effects due to transient high blood concentration of drug caused by repeated oral administration and to provide sustained drug release for an extended period of time from the drug reservoir or matrix [2-5]. However, few drugs can be administered this way due to the barrier function of the skin. The skin is an attractive route for drug administration because it can avoid the first-pass hepatic metabolism of drugs intended for systemic action, thereby allowing for potentially lower drug doses and reduced side effects. The stratum corneum, the outermost layer of the skin, is the primary skin barrier, with a structure like a brick wall: the corneocytes are bricks surrounded by the mortar of the intercellular lipid lamellae. The highly organized crystalline lipid lamellae play an essential role in the barrier properties of the stratum corneum. Many techniques can disrupt and weaken the highly organized intercellular lipids to enhance drug transport across the intact skin or to increase the driving force for drug permeation.

One of the most controversial methods is the use of vesicle formulations as skin delivery systems. Penetration enhancers can also increase the permeability of the stratum corneum [2-5]. Some of the intrinsic ingredients in these systems, such as fatty acids, phospholipids, and surfactants, enhance penetration through the skin, thus increasing the absorption of the drug.

Many new penetration enhancers have been developed to improve percutaneous absorption of drug. One of these, ethylenevinyl acetate (EVA), which is a biocompatible, heat-processible, flexible and inexpensive material, has been used for transdermal drug delivery [3]. In the present study, we therefore tested whether an EVA matrix system could improve the transdermal delivery of torasemide. We performed release studies according to loading dose, temperature, and plasticizer content. To increase skin permeation, we optimized the use of a penetration enhancer in the EVA matrix and measured drug permeation across rat skin. This study was carried out to evaluate the possibility of developing the EVA matrix system for transdermal delivery of torasemide by studying its in vitro release characteristics.

\section{EXPERIMENTAL}

\section{Materials}

Torasemide was supplied by Roche Korea Co., Ltd. Ethylene-vinyl acetate (EVA, $40 \%$ vinyl acetate) was purchased from Aldrich Chemical Co, Inc (USA). Acetyl tributyl citrate (ATBC), tributyl citrate (TBC), acetyl triethyl citrate (ATEC) and triethyl citrate (TEC) were purchased from Morflex, Inc (USA). Diethyl phthalate (DEP) and di-n-butyl phthalate (DBP) were from Junsei Chemical Co, Ltd. (Japan). Lauric acid, oleic acid and caprylic acid were purchased from Tokyo Kasei Kogyo Co, Ltd (Japan). 2-Pyrrolidone was purchased from Acros Organics (USA). Myristic acid, linoleic acid, 1-methyl-2-pyrrolidone, polyoxyethylene-2-stearyl ether, polyoxyethylene-2-oleyl ether and polyoxyethylene-23-lauryl ether were purchased from Sigma-Aldrich Co, Ltd (USA). Macrogol-6-glycerides, caprylocaproyl macrogol-8-glycerides, propylene glycol laurate and propylene glycol monolaurate were gifts from Gattefose (France). Stearic acid and palmitic acid were purchased from Kanto Chemical Co, Inc (Japan). Acetonitrile and methanol, HPLC grade, were purchased from JT Baker, Inc (USA). All the reagents were of analytical grade and used without further purification.

\section{Determination of drug solubility}

Trop J Pharm Res, December 2011;10 (6):714 
Excess amounts of torasemide were equilibrated with saline containing various concentrations of PEG 400. Each solution was shaken at $37^{\circ} \mathrm{C}$ for $24 \mathrm{~h}$ in shaking incubator. The solution was then filtered through $0.45 \mu \mathrm{m}$ membrane filter. The concentration of torasemide was determined at $290 \mathrm{~nm}$, after appropriate dilution, using a UV spectrophotometer (Vectra ES/12, Hewlett Packard (U.S.A.).

\section{HPLC determination of torasemide}

Torasemide was assayed by high pressure liquid chromatography (HPLC) method (Waters 484, USA). The HPLC system consisted of Degaser (DG-1210, Japan), a pump (Knauer, DE/K-120, USA), an injector (Alcott, US/708-autosampler, U.S.A.), Restek $\mathrm{C}_{18}$ column $(250 \times 4.6 \mathrm{~mm}, 5 \mathrm{um})$, UV detector (Waters 484, USA) and an integrator (Youngin Scientific Co, Ltd, D520A, Korea). The mobile phase was a combination of methanol: distilled water (40: $60 \mathrm{v} / \mathrm{v}$ ) and the column was maintained at ambient temperature. A flow rate of $1.5 \mathrm{ml} / \mathrm{min}$ yielded an operational pressure of $\sim 1000$ psi. The UV detector was operated at a wavelength of $290 \mathrm{~nm}$. Under these conditions, the torasemide peak appeared at the retention time of $3.647 \mathrm{~min}$.

\section{Preparation of drug-containing EVA matrix}

Two grams of EVA copolymer beads was dissolved in $20 \mathrm{ml}$ of chloroform in a beaker, and drug solution (torasemide-methanol) was added. This mixture was poured onto a glass plate and the solvent allowed to be evaporated at room temperature over a $24-\mathrm{h}$ period. The matrix was then removed from the plate.

\section{Release of torasemide from the EVA matrix}

The in vitro release of torasemide from the EVA matrix was examined in a Franz diffusion cell. A unit of EVA matrix was clamped on the cell cap, i.e., the upper side of the receptor cell. The diameter of the cell cap was $2 \mathrm{~cm}$, providing $3.14 \mathrm{~cm}^{2}$ effective constant area between the matrix and the bulk solution of 21 ml. PEG 400-water solution (40\%) was used as receptor medium. The receptor was maintained at $37{ }^{\circ} \mathrm{C}$ with a circulating water jacket and stirred constantly at $380 \mathrm{rpm}$. Prior to the experiment, the system was tested to remove any remaining air bubbles in the receptor site. At a predetermined time, the whole solution from the receptor cell was taken and replaced with fresh solution. The cumulative amount of torasemide released from the drug-EVA matrix was determined at $290 \mathrm{~nm}$.

The effect of drug concentration on its release from the EVA matrix was studied at the following drug concentrations: 1.0, 2.0 and 3.0 $\% w / w$ while the effect of temperature on drug release was studied at $27,32,37$ and $42{ }^{\circ} \mathrm{C}$. Each determination was carried out in triplicate.

\section{Preparation and of torasemide from drug- EVA matrix containing the plasticizer}

Plasticizers reduce the brittleness, improve flow, impart flexibility and increase toughness, strength, tear resistance and impact resistance of the polymer. Increasing the amount of plasticizer could lead to an increase in free film elongation and a decrease in tensile strength and Young's modulus. Alkyl citrates - acetyl tributyl citrate (ATBC), tributyl citrate (TBC), acetyl triethyl citrate (ATEC), and triethyl citrate (TEC) - and phthalates diethyl phthalate (DEP) and di-n-butyl phthalate (DBP) - were used. In each case, the plasticizer was dropped into the drugcontaining EVA solution and mixed for $1 \mathrm{~h}$. This method was chosen in order to produce large defect-free membrane samples with no orientation of the molecules. The release of torasemide from the EVA matrix containing plasticizer was studied at $2.0 \%$ loading dose and $37^{\circ} \mathrm{C}$. Each determination was carried out in triplicate.

Enhancement factor (EF) was calculated using Eq 1.

$$
E F=R p / R c \ldots \ldots(1)
$$

Trop J Pharm Res, December 2011;10 (6):715 
where $R p$ is the flux of EVA matrix containing plasticizer and $R c$ is the flux of EVA matrix not containing plasticizer. .

\section{Skin preparation}

A male rat (Sprague Dawley rat strain) was sacrificed by excess etherization. The hair was carefully removed from the abdominal area with an electric clipper. A square section of the abdominal skin was then excised, and the adhering fat and other visceral debris in the skin were carefully removed from the undersurface with tweezers [5]. The excised abdominal rat skin was used immediately. The experiments were carried out in accordance with the "Guiding Principles in the Use of Animals in Toxicology" adopted by the Society of Toxicology (USA) in July 1989 and revised in March 1999. The Animal Care Committee of Chonnam National University (Gwangju, Republic of Korea) approved the study design and conduct of this study (ref no. 2009-12).

\section{Preparation of EVA matrix containing an enhancer}

EVA copolymer beads ( $2 \mathrm{~g}$ ) were dissolved in $20 \mathrm{ml}$ of chloroform in a glass beaker. Appropriate amount of drug (40mg) was dissolved in $4 \mathrm{ml}$ of methanol and the enhancer added. The mixed polymer solution was poured onto a glass plate for casting, and the solvent was allowed to be evaporated at room temperature over a $24-\mathrm{h}$ period. The membrane was taken from the plate and dried at room temperature.

\section{Permeation of torasemide through rat skin from EVA matrix}

To improve the penetration of torasemide from EVA matrix across skin, various enhancers, such as propylene glycol derivatives, fatty acids, glycerides, pyrrolidones and non-ionic surfactants, were incorporated at $5 \%$ concentration into the torasemide-EVA matrix.

The effect of the enhancers on skin penetration was evaluated using a Franz diffusion cell fitted with excised rat skin. The freshly excised full-thickness skin was mounted on the receptor site of the diffusion cell with the stratum corneum side facing upwards, i.e., the donor compartment, and the dermal side facing the receptor compartment. An appropriate size $(2.5 \mathrm{~cm})$ of the matrix was placed on the stratum corneum side, covered with a round glass plate, and clamped. The receptor medium was $40 \%$ PEG 400 solution to achieve sink conditions and was maintained at $37{ }^{\circ} \mathrm{C}$ by a circulating water bath. Test samples were withdrawn at predetermined time intervals and immediately replaced on each occasion with an equal volume of fresh medium. Penetrated quantities of torasemide were analyzed by HPLC at $290 \mathrm{~nm}$. Each determination was carried out in triplicate. The enhancement factor (EF) was calculated Eq 2.

$$
E F=R e / R c
$$

where $R e$ is the flux of EVA matrix containing enhancer and $R c$ is the flux of not containing enhancer

\section{Data analysis}

Permeation rate was calculated from the slope of the linear region of the permeation profile. The flux was calculated from the slope of the linear region of the $Q$ versus $t$ permeation profile. A linear profile was observed during the 16-h experiment and the slope of the linear portion of the curve was determined by linear regression. Statistical analysis was performed using ANOVA, with Student-Newman-Keuls employed as a post-hoc test. SigmaStat software (version 3.5, Systat software, Richmond, CA, USA) was used for all analysis. A $p$-value of less than 0.05 was considered statistically significant. All values were expressed as mean \pm standard deviation.

\section{RESULTS}

\section{Solubility of torasemide}

The solubility of torasemide increased as the volume fraction of PEG 400 increased,

Trop J Pharm Res, December 2011;10 (6):716 
showing the highest solubility at $40 \%$ PEG 400 (Fig 1).

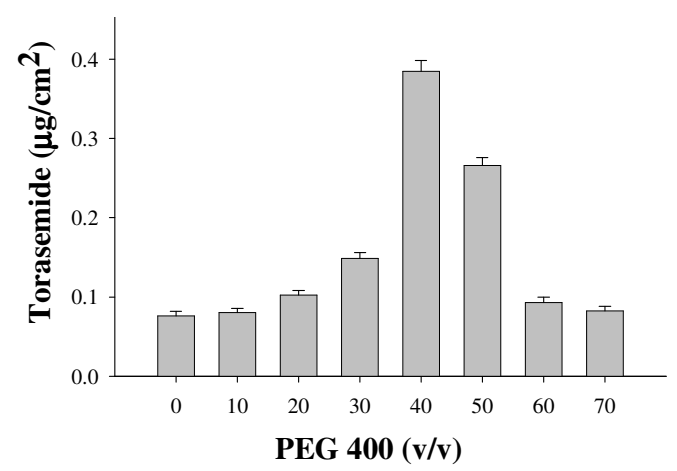

Fig 1: Solubility of torasemide in various PEG 400 solutions of varying concentration

\section{Effect of drug loading dose on drug release}

A characteristic of the drug release profile of matrix-type drug delivery system can be represented by Higuchi's equation [6]. The release from a planar system having dispersed drug in a homogeneous matrix should follow the relationship in Eq 3.

$$
Q=\left[D\left(2 A-C_{s}\right) C_{s} t\right]^{1 / 2}
$$

where $Q$ is the amount of drug released after time, $t$, per unit exposed area, $D$ is the diffusivity of the drug in the matrix, $A$ is the initial drug concentration, and $\mathrm{C}$ is the drug solubility in the matrix. Higuchi later derived a similar relationship for planar release from a granular matrix system in which diffusion occurs through channels, as in Eq 4 [7]:

$Q=\left[D / T\left(2 A-\varepsilon C_{s}\right) C_{s} t\right]^{1 / 2}$

where $D$ and $C s$ refer to diffusivity and solubility in the permeability field, respectively; $\mathrm{T}$ the tortuosity of the matrix and $\varepsilon$ the porosity of the matrix. Although the two equations are for different mechanisms, they both describe drug release as being linear with the square root of time, as in Eqs $5-7$.

$$
\mathrm{Q}=\mathrm{K}_{\mathrm{H}} \cdot \mathrm{t}^{1 / 2}
$$

where, for the homogeneous matrix system:
$K_{H}=\left[D\left(2 A-C_{s}\right) C_{s}\right]^{1 / 2}$

and for the granular matrix system:

$K_{H}=\left[D / T\left(2 A-\varepsilon C_{S}\right) C_{S}\right]^{1 / 2}$

The validity of the relationships has been confirmed experimentally by a number of researchers using various systems $[8,9]$.

The release profile of torasemide from the EVA matrix at different drug loads over a 4-h period is shown in Fig 2. The cumulative amount of torasemide released $(Q)$ versus the square root of time $\left(t^{1 / 2}\right)$ plot shows good linearity for all three concentrations. As expected from Equation 9 and 10, a plot of $\mathrm{Q} / \mathrm{t}^{1 / 2}$ versus the square root of loading dose (A) yielded a straight line (Fig 2). Q/t $t^{1 / 2}$ increased in direct proportion to the increase in the loading dose of torasemide.

\section{Effect of medium temperature on drug release}

The dependency of the drug release profile on temperature is shown in Fig 3. The cumulative amount of drug released ( $Q$ ) is plotted versus the square root of time $\left(\mathrm{t}^{1 / 2}\right)$. After an initial period of drug release, release became approximately linear with respect to $t^{1 / 2}$. The steady-state rate of drug release $\left(Q / t^{1 / 2}\right)$ was estimated from the slope of the linear $Q-t^{1 / 2}$ profile from 0 to $16 \mathrm{~h}$. At higher temperatures, drug release $\mathrm{Q} / \mathrm{t}^{1 / 2}$ values increased. It should be noted that the rate of drug release increased about 1.65-fold when the temperature of the drug release system was raised from 27 to $42{ }^{\circ} \mathrm{C}$. But for practical purpose, $37^{\circ} \mathrm{C}$ was chosen to reflect the temperature of the stratum corneum.

Permeability coefficient can then be defined by Eqs 8 and 9. 


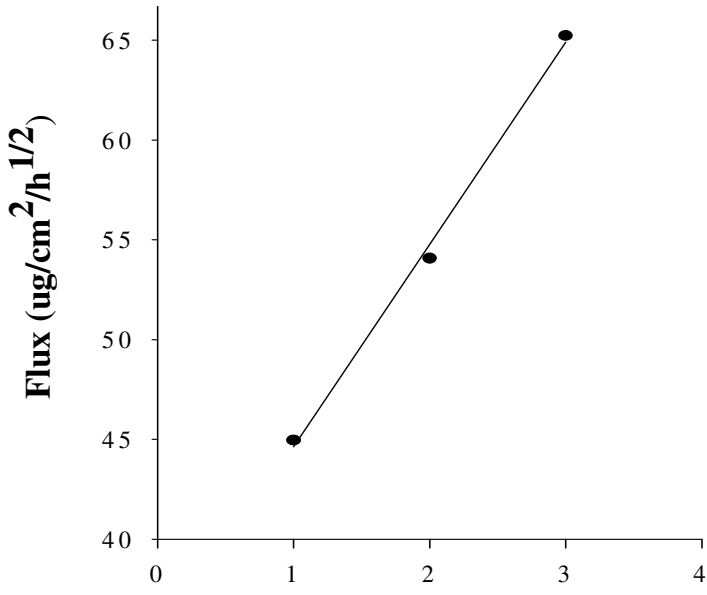

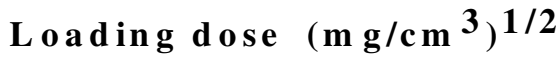

Fig 2: Relationship between torasemide flux and drug loading dose of EVA matrix at $37^{\circ} \mathrm{C}$.

$\mathrm{P}=$ Flux/Solubility

$P=P_{0} \times e^{-E a / R T}$

$\log P=\log P_{0}-E_{a} / R / 2.303 / 1000 \times 1000 / T \ldots$ (10)

As expected from Equation 8, a plot of $\log P$ versus 1000/T yielded a straight line (Fig 3).

Slope $=-E_{a} / R / 2.303 \times 1 / 1000$

$\mathrm{E}_{\mathrm{a}}=$-Slope $\mathrm{xR} \times 2.303 \times 1000 \mathrm{cal}=-$ Slope $\mathrm{x}$ $1.987 \times 2.303 \mathrm{kcal}$

The $E_{a}$ (activation energy), which was measured from the slope of $\log P$ versus $1000 / \mathrm{T}$ plots (Eq 12), was $14.9 \mathrm{kcal} / \mathrm{mol}$ for 2.0 $\%$ loading dose in EVA matrix.

\section{Effect of plasticizers on the drug release from EVA matrix}

In the case of citrate group, there was a slight increase in drug release. On the other hand, phthalate plasticizers produced a greater increase in drug release rate than the citrate plasticizers (Table 1).

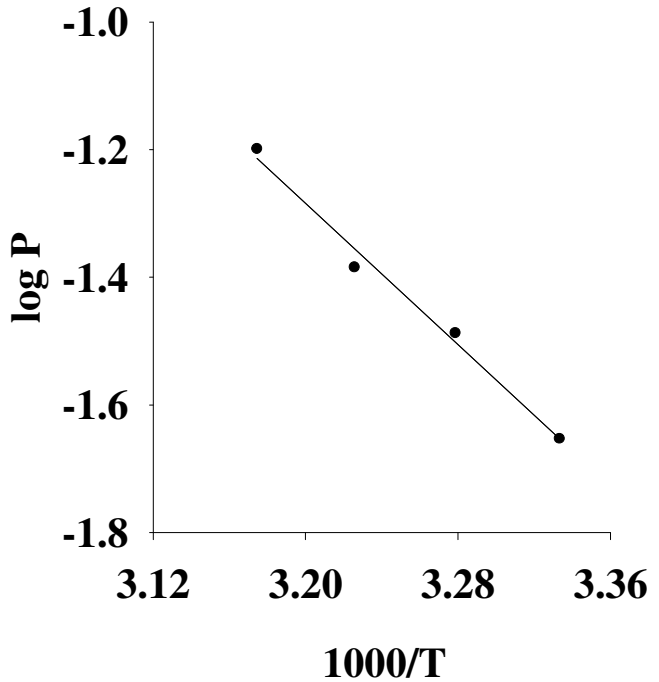

Fig 3: Effect of temperature on torasemide release from EVA matrix containing $2 \%$ loading dose.

Table 1: Effect of plasticizers on torasemide release from EVA matrix with $2.0 \%$ loading dose at $37^{\circ} \mathrm{C}($ mean $\pm \mathrm{SD}, \mathrm{n}=3)$

\begin{tabular}{lc}
\hline Plasticizer & Flux \pm S.D $\left(\mathrm{ug} / \mathrm{cm}^{2} / \mathrm{hr}^{1 / 2}\right)$ \\
\hline Control & $23.05 \pm 1.54$ \\
ATBC & $23.93 \pm 1.15$ \\
TBC & $24.46 \pm 1.95$ \\
TEC & $29.28 \pm 2.41$ \\
ATEC & $29.07 \pm 0.79$ \\
DBP & $24.43 \pm 1.62$ \\
DEP & $30.38 \pm 3.87$ \\
\hline
\end{tabular}

Effect of enhancers on the permeation of torasemide through rat skin

Table 2 shows the enhancement factor of the permeation enhancers on torasemide-EVA matrix. The flux of torasemide from the EVA matrix containing polyoxyethylene 2-oleyl ether $\left(1.59 \pm 0.03 \mathrm{ug} / \mathrm{cm}^{2} / \mathrm{hr}\right)$ was significantly increased than in control matrix $(0.57 \pm 0.01$ $\left.\mathrm{ug} / \mathrm{cm}^{2} / \mathrm{h}, p<0.05\right)$, as shown in Table 2 . Amongst all the enhancers used in this study, polyoxyethylene-2-oleyl ether showed the highest enhancing effect (2.79-fold).

Trop J Pharm Res, December 2011;10 (6):718 
Table 2: Enhancement factor (EF) of various permeation enhancers in EVA matrix system

\begin{tabular}{lcc}
\hline Permeation enhancer & $\begin{array}{c}\text { Flux } \\
\left(\mathrm{ug} / \mathrm{cm}^{2} / \mathrm{h}\right)\end{array}$ & EF \\
\hline $\begin{array}{l}\text { Control } \\
\text { Polyoxyethylene 23-lauryl } \\
\text { ether }\end{array}$ & $1.57 \pm 0.01$ & 1.00 \\
$\begin{array}{l}\text { Polyoxyethylene 2-stearyl } \\
\text { ether }\end{array}$ & $1.14 \pm 0.02$ & 2.28 \\
$\begin{array}{l}\text { Polyoxyethylene 2-oleyl } \\
\text { ether }\end{array}$ & $1.59 \pm 0.03$ & 2.00 \\
Oleic acid & $0.99 \pm 0.02$ & 1.74 \\
Linoleic acid & $1.18 \pm 0.02$ & 2.07 \\
Caprylic acid & $1.11 \pm 0.02$ & 1.95 \\
Lauric acid & $1.25 \pm 0.02$ & 2.20 \\
Myristic acid & $0.86 \pm 0.01$ & 1.51 \\
$\begin{array}{l}\text { Oleyl macrogol-6 } \\
\text { glycerides }\end{array}$ & $1.03 \pm 0.02$ & 1.81 \\
$\begin{array}{l}\text { Caprylocaproyl macrogol- } \\
\text { 8 glycerides }\end{array}$ & $0.87 \pm 0.01$ & 1.40 \\
$\begin{array}{l}\text { Propylene glycol mono } \\
\text { caprylate }\end{array}$ & $1.17 \pm 0.02$ & 2.05 \\
$\begin{array}{l}\text { Propylene glycol laurate } \\
\text { Propylene glycol mono }\end{array}$ & $1.22 \pm 0.03$ & 2.14 \\
laurate & $1.03 \pm 0.02$ & 1.81 \\
NMP & $1.32 \pm 0.03$ & 2.32 \\
$\begin{array}{l}\text { 2-Pyrrolidone } \\
\text { PVP }\end{array}$ & $1.12 \pm 0.03$ & 1.96 \\
\hline a & $0.60 \pm 0.01$ & 1.05 \\
\hline
\end{tabular}

\section{DISCUSSION}

\section{Effect of medium temperature on drug release}

This observation clearly shows that the release of torasemide from the EVA matrix is an energy-linked process [10]. The increase in release with increasing temperature suggests that release characteristics of the copolymer would change over the body temperature range. This finding indicates that special precautions should be taken with regard to monitoring body temperature in practical applications.

\section{Effect of plasticizers on the drug release from EVA matrix}

Generally, plasticizers increase the amount of drug release by increasing the chain mobility of the polymer. The plasticizers will interpose between the polymer chains and interact with the forces to extend and soften the polymer matrix [11]. The selection of a suitable plasticizer and its concentration has a profound influence on the mechanical properties as well as on the permeability of drugs [11]. Increasing the amount of plasticizer could lead to an increase in free film elongation and a decrease in tensile strength. A strong interaction between a drug and a polymer has been reported to significantly influence drug release through a polymeric film [12].

\section{Effect of enhancers on the permeation of torasemide through rat skin}

Human skin is an effective, selective barrier to chemical permeation [13] and is a strong barrier against the penetration of external drugs when applied as TDDS. Thus, to maximize drug flux, it is usually necessary to reduce skin barrier properties, although the follicular route may also be important [13]. To achieve high permeation rates and attain therapeutic dose levels, it is necessary to overcome the barrier properties of the stratum corneum. Therefore, physical or chemical penetration enhancers have become useful [14-15].

Compared with control, saturated fatty acid group of permeation enhancers only slightly increased drug penetration rate. Among this group, lauric acid showed the greatest increase in penetration rate. Linoleic acid also significantly increased the penetration rate of the drug from EVA matrix. The saturated fatty acid group showed a slightly higher effect on penetration rate than the unsaturated fatty acid.

In skin pre-treated with non-ionic surfactant, the stratum corneum is loosely layered and the intercellular spaces are wide [16]. 
Polyoxyethylene-2-stearyl ether, polyoxyethylene-23-lauryl ether and polyoxyethylene-2-oleyl ether produced increased penetration rate. In other experiments carried out in our laboratory, polyoxyethylene-2-oleyl ether showed the highest penetration enhancement effect.

The non-ionic surfactants affect the permeability of several biological membranes including skin [17] and can thus enhance the skin penetration of other compounds in the formulation. Therefore, in recent years they have been employed to enhance the permeation rates of several drugs [16-18] and have been studied to determine the mechanism of the effect of non-ionic surfactants. In skin pre-treated with non-ionic surfactant, the stratum corneum was loosely layered and the intercellular spaces were wide [16]. Polyoxyethylene-2stearyl ether, polyoxy-ethylene-23-lauryl ether and polyoxy-ethylene-2-oleyl ether produced increased penetration rate.

Caprylocaproyl macrogol-8-glyceride increases the passive transport of drug molecules. It shows high tolerance and low toxicity and is included as a pharmaceutical excipient in European Pharmacopoeia in 2003. Oleyl macrogol-6-glyceride is a PEG derivative, used as a co-surfactant in pharmaceutical systems such as microemulsions. The penetration of PGs through the tissue could alter the thermodynamic activity of the drugs in the vehicle, which would in turn modify the driving force for diffusion. PGs may partition into the tissue, facilitating uptake of the drug into skin, and there may be minor disturbances to intercellular lipid packing within the stratum corneum bilayers [19]. Propylene glycol laurate showed a significant penetration rate of torasemide. Within each study, significant differences were observed among the formulations.

In terms of the mechanism of action, the pyrrolidones partition well into the human stratum corneum. Within the tissue, they may act by altering the solvent nature of the membrane, and pyrrolidones have been used to generate 'reservoirs' within skin membranes. Such a reservoir effect offers the potential for sustained release of a permeant from the stratum corneum over an extended time period [19].

The flux of torasemide from the EVA matrix containing polyoxyethylene 2-oleyl ether $\left(1.59 \pm 0.03 \mathrm{ug} / \mathrm{cm}^{2} / \mathrm{hr}\right)$ was significantly increased compared with the control group $\left(0.57 \pm 0.01 \mathrm{ug} / \mathrm{cm}^{2} / \mathrm{hr}\right) \quad(\mathrm{p}<0.05) \quad($ Table 2). Among all enhancers used in this study, polyoxyethylene-2-oleyl ether showed the highest enhancing effect by 2.79 fold.

\section{CONCLUSION}

Among the plasticizers used, diethyl phthalate was the most suitable in terms of enhancement torasemide release while among the enhancers used, polyoxyethylene2-oleyl ether was the most effective in enhancing the penetration of torasemide into the skin. Thus, for enhanced controlled transdermal delivery of torasemide, an EVA matrix modulated with suitable plasticizer and penetration enhancer is feasible.

\section{REFERENCES}

1. Burnier M. Medication adherence and persistence as the cornerstone of effective antihypertensive therapy. Am J Hypertension 2006; 19: 11901196.

2. Shin SC, Kim J, Kim WJ, Kim SJ, Cho CW. Development and biopharmaceutical valuation of qinupramine-EVA matrix containing penetration enhancer for the enhanced transdermal absorption in rats. Pharm Devel Technol 2007; 12: 429-436.

3. Shin SC and Lee HJ. Enhanced transdermal delivery of triprolidine from the ethylene-vinyl acetate matrix. Eur J Pharm Biopharm 2002; 54: 325328.

4. Loan $H$, Nguyen $P$, Joke $A B$. Vesicles as a tool for transdermal and dermal delivery. Drug Discovery Today: Tec. 2005; 2: 67-74.

5. Durrhein H, Flynn GL, Higuchi WI, Behl CR. Permeation of hairless mouse skin I: experimental methods and comparison with human epidermis permeation by alkanols. J. Pharm Sci 1980; 69: 781-786. 
6. Higuchi T. Rate of release of medicaments from ointment bases containing drug in suspension. J Pharm Sci 1961; 50: 874-875.

7. Higuchi T. Mechanism of sustained-action medication. Theoretical analysis of rate of release of solid drugs dispersed in solid matrices. J Pharm Sci 1963; 52: 1145-1149.

8. Farhadieh B, Boradkin S, Buddenhagen J. Drug release from methyl acrylate-methyl methacrylate copolymer matrix I: Kinetics of release. $J$ Pharm Sci 1971; 60; 209-211.

9. Farhadieh B, Boradkin S, Buddenhagen J. Drug release from methyl acrylate-methyl methacrylate copolymer matrix II: Control of release rate by exposure to acetone vapor. J Pharm Sci 1971; 60: 212-215.

10. Miyazaki S, Ishii K, Sugibayashi K, Morimoto $Y$, Takada M. Antitumor effect of ethylene-vinyl acetate copolymer matrices containing 5fluorouracil on Ehrlich Ascites carcinoma in mice. Chem Pharm Bull 1982; 30: 3770-3775.

11. Crawford RR, Esmerian OK. Effect of plasticizers on some physical properties of cellulose acetate phthalate films. J Pharm Sci 1971; 60: 312-314.

12. Jenquin MR, Liebowitx SM, Sarabia RE, McGinity JW. Physical and chemical factors influencing the release of drugs from acrylic resin films. $J$ Pharm Sci 1990; 79: 811-816.
13. Barry BW. Properties that influence percutaneous absorption; Dermatological Formulations. Marcel Dekker. 2001; 127-233.

14. Choi JS, Shin SC. Enhanced bioavability of ambroxol by transdermal administration of the EVA matrix containing penetration enhancer in rats. Biomol. Therap 2010; 18:106-110.15. Golden GM, Mckie JE, Potts RO. Role of stratum corneum lipid fluidity in transdermal drug flux. $J$ Pharm Sci 1987; 76: 25-28.

16. Shin SC, Cho CW, Oh IJ. Effects of non-ionic surfactants as permeation enhancers towards piroxicam from the poloxamer gel through rat skins. Int J Pharm 2001; 222: 199-203.

17. Lopez A, Llinares $F$, Cortell C, Herraez $M$. Comparative enhancer effects of span 20 with Tween 20 and Azone on the in vitro percutaneous penetration of compounds with different lipophilicities. Int J Pharm 2000; 202: 133-140.

18, Cho CW, Choi JS, Shin SC. Enhanced local anesthetic efficacy of bioadhesive ropivacaine gels. Biomol Therap 2011; 19: 357-363.

19. Williams AC, Barry BW. Penetration enhancers. Adv Drug Delivery News 2004; 56: 603-618. 